\title{
DELINQUÊNCIA AUTO-REVELADA EM SERVIÇO DE MEDIDAS SOCIOEDUCATIVAS EM MEIO ABERTO NO BRASIL
}

\author{
Lylla Cysne Frota D'Abreu \\ Psicóloga formada pela Universidade de São Paulo - Faculdade de Filosofia, Ciências e Letras de \\ Ribeirão Preto. Mestre em Ciências Médicas (Saúde Mental) pela Universidade de São Paulo - \\ Faculdade de Medicina de Ribeirão Preto. Doutoranda pela Universidade de Potsdam (Alemanha) - \\ Instituto de Psicologia.
}

\begin{abstract}
Resumo
A pesquisa internacional aponta que a delinquência auto-revelada é uma estratégia bem-sucedida de aprimorar a coleta de dados na identificação das chamadas "cifras negras", ou seja, delitos que não são reportados ao sistema de justiça. Esta técnica, no entanto, é ainda pouco utilizada no Brasil. Mediante pesquisa documental a partir de dados de arquivo, este estudo caracterizou uma amostra de 211 adolescentes que cumpriam medida socioeducativa em meio aberto quanto à delinquência não-oficial e variáveis sócio-demográficas. Os resultados mostraram que adolescentes em conflito com a lei têm engajamento delinquente com polimorfismo e intensidade expressivamente maior do que os órgãos oficiais são capazes de identificar. A delinquência auto-revelada aperfeiçoa a coleta de dados, fornece taxas mais próximas da realidade quanto ao engajamento na delinquência e guia estratégias mais assertivas de intervenção nos serviços.
\end{abstract}

Palavras-chave: delinquência juvenil, auto-relato, medidas socioeducativas.

\section{SELF-REPORTED DELINQUENCY IN A PROBATION SERVICE IN BRAZIL}

\begin{abstract}
International research shows that self-reported delinquency is a successful strategy to improve data collection on the identification of the so-called "dark figure", ie, offenses that are not reported to the justice system. This technique, however, is still little used in Brazil. Through documentary research from data archive, this study described the socio-demographic variables and the severity of unofficial delinquency of a sample of 211 adolescents who attended a probation service in Brazil. The results showed that adolescents in conflict with the law have delinquent engagement with higher polymorphism and intensity than the official data are able to identify. Self-reported delinquency can improve data collection, provide more reliable rates and guide more assertive intervention actions in these services.
\end{abstract}

Keywords: juvenile delinquency, self report, socioeducative measures. 


\title{
AUTO-REPORTE DE LA DELINCUENCIA EN SERVICIO DE MEDIDAS SOCIOEDUCATIVAS EN LIBERTAD EN BRASIL
}

\begin{abstract}
Resumen
La investigación internacional demuestra que la delincuencia auto-reportada es una estrategia exitosa para mejorar la recopilación de datos sobre la identificación de la llamada "cifra negra", es decir, delitos que no son denunciados a la justicia. Esta técnica, sin embargo, es aún poco utilizado en Brasil. A través de la investigación documental de archivo de datos, este estudio describe las variables sociodemográficas y la gravedad de la delincuencia no oficial de una muestra de 211 adolescentes que asistían a un servicio de medidas socioeducativas en libertad en Brasil. Los resultados mostraron que los adolescentes en conflicto con la ley tienen participación delincuente con mayor polimorfismo y intensidad que los datos oficiales son capaces de identificar. El auto-reporte de la delincuencia puede mejorar la recopilación de datos, ofrecer tasas más fiables y guiar intervenciones más firme en estos servicios.
\end{abstract}

Palabras clave: delincuencia juvenil, auto-reporte, medidas socioeducativas.

\section{INTRODUÇÃO}

A delinquência juvenil é um fenômeno comum em sociedades ocidentais. Na realidade, o que se estima é que pelo menos $60 \%$ dos adolescentes já cometeram algum ato infracional em algum momento da vida (Fréchette \& LeBlanc, 1987). Os custos da delinquência são enormes tanto para a sociedade, quando calculados em termos de danos à propriedade, lares violados e danos físicos e psíquicos nas vítimas, quanto para o infrator, com vidas devastadas pelo uso de drogas, pelo engajamento em violência mútua, por comportamentos imprudentes nas ruas e por internação em instituições onde eles podem ser brutalizados, trazendo consequências que podem perdurar por toda uma vida (Carroll, 2009).

O termo delinquência refere-se ao engajamento do adolescente em comportamento ilegal. Para manifestação adulta, o termo usado é "criminal" ou "criminoso" (Hinshaw \& Lee, 2003; Liu, 2004). Para a realização de pesquisas na área, a operacionalização do conceito de delinquência é feita a partir de indicadores que representam o fenômeno, como prevalência, incidência, persistência, desenvolvimento, gravidade, duração, precocidade, polimorfismo, entre outros (Le Blanc \& Fréchette, 1989).

Usualmente, as pesquisas sobre delinquência se baseiam em dois tipos de medida: os dados oficiais do sistema de justiça e a delinquência auto-revelada (Moffitt, 1993). Os dados oficiais, entretanto, apresentam uma série de limitações. Primeiro, negligenciam informações relevantes para o profissional da 
área, como por exemplo, padrões de comportamento "pré-delinquente" (Hinshaw \& Lee, 2003). Segundo, para um delito fazer parte das estatísticas, ele deve ser a) detectado, b) notificado às autoridades policiais e, c) registrado no boletim de ocorrência. Registros policiais, no entanto, são apenas uma estimativa parcial dos crimes ocorridos e devem ser interpretados com cautela: refletem mais o fenômeno social de notificação dos crimes, que um retrato fiel dos crimes ocorridos de fato em determinado local (LeBlanc, Côté \& Loeber, 1991). Terceiro, dados oficiais são tendenciosos: alguns delitos são mais fáceis de serem descobertos; outros delitos menos prováveis de se tornarem um processo judicial, porque se tem maior tolerância a eles; e alguns grupos de adolescentes (jovens negros no Brasil, por exemplo) são mais frequentemente controlados e pegos (Pöge, 2007).

No Brasil, o primeiro relatório com dados oficiais quanto ao perfil dos adolescentes que cumprem medidas socioeducativas, incluindo as de meio aberto, foi disponibilizado pelo Instituto Latino-Americano das Nações Unidas para Prevenção do Delito e Tratamento do Delinquente (ILANUD) em 2007. Até então só havia relatórios com as medidas socioeducativas em meio fechado. Lamentavelmente, apenas $30 \%$ das Comarcas do país responderam às solicitações do ILANUD. Deste conjunto de varas que participaram da pesquisa, uma proporção de $20 \%$ não foi inserida no banco de dados, pois a verificação e a crítica do material identificaram situações que impossibilitavam a consideração dos dados (ILANUD, 2007).

Dos dados obtidos e disponibilizados, revela-se que a maior parte dos adolescentes que cumpre medida socioeducativa no Brasil é do sexo masculino (88\%) e em sua maioria tem de 16 a 17 anos (44\%). A maior parte dos jovens da amostra se envolveu em atos infracionais correspondentes a crimes contra o patrimônio $(62,8 \%)$ : roubos $(25,4 \%)$ e furtos $(16,9 \%)$. Em menor número aparecem os crimes contra a pessoa/costumes $(13,6 \%)$, dentre eles, lesão corporal (4,1\%) e homicídio (2,3\%), crimes/delitos associados ao porte/uso/tráfico de drogas (5,2\%) e outros delitos (10,3\%). As medidas em meio aberto são as mais comuns: Prestação de Serviço à Comunidade (PSC) e Liberdade Assistida (LA) correspondem a 73,7\% do total de adolescentes que cumprem medidas socioeducativas no país e a $88 \%$ dos adolescentes que vivem no interior. A medida de LA é a medida cumprida por quase $40 \%$ do total de adolescentes. 
Este é, entretanto, apenas um retrato dos índices que chegam até a justiça. Uma maneira de aprimorar a coleta de dados e de se aproximar dos números reais da delinquência é coletar informações através do relato confidencial dos próprios jovens, a delinquência auto-revelada. Essa forma de estudo, iniciada em torno da década de 50, trouxe um grande avanço para o estudo/compreensão da personalidade do adolescente infrator. Ela é realizada através de questionário auto-administrado ou de entrevistas semi-estruturadas. As últimas são particularmente vantajosas porque em contato direto com o sujeito, o aplicador pode produzir condições que encorajam a comunicação e diminuam as resistências específicas e gerais quanto à revelação do delito pelo adolescente. Além disso, o contato direto controla problemas de leitura, falta de concentração, erros motivacionais (fadiga), e checa a validade e confiabilidade das respostas (Ex: testando uma frequência que pareça surpreendente, confrontando o entendimento em caso de hesitação ou de sinais de dificuldade, e confrontando a veracidade de um delito questionando sobre seu modus operandi) (Le Blanc \& Fréchette, 1989).

As estimativas de auto-relato são substancialmente maiores que aquelas baseadas em dados oficiais, corroborando que dados oficiais da justiça constituem apenas uma fração real de comportamento delinquente existente (Elliott, Huizinga \& Morse, 1986). O auto-relato parece, portanto, ser muito conveniente, não só porque a maioria dos atos não chega ao sistema de justiça (LeBlanc et al., 1991), mas também porque informações quanto à gravidade de engajamento na delinquência podem ser obtidas com mais detalhes: número e tipo de delitos já cometidos, idade de início, frequentação de pares desviantes, motivação utilitária ${ }^{1}$, uso de armas, presença de cúmplices, presença de intoxicação por drogas no momento do delito, presença de antecedentes, presença de violência contra a pessoa, presença de planejamento, entre outros (Le Blanc \& Fréchette, 1989).

No Brasil, é evidente a escassez de estudos empíricos que enfoquem medidas de comportamentos anti-sociais e delitivos auto-revelados, tanto com a

\footnotetext{
${ }^{1}$ Motivação utilitária refere-se ao desejo de obter bens materiais através do delito. Ela se contrapõe à motivação hedonista, cujo principal objetivo do adolescente é obter prazer, aventura e rompimento de limites sociais. A segunda traz menor prejuízo ao adolescente e tende a ter remissão espontânea na entrada da vida adulta, quando outros comportamentos pró-sociais passam a ser reforçados. Motivação hedonista é um indicador do que Moffit (1993) chamou de carreira criminal transitória.
} 
população em geral, quanto com adolescentes que cumprem medidas socioeducativas. Ainda existe no país uma cultura nos serviços que atendem adolescentes infratores de que não se deve falar com o adolescente infrator sobre os delitos praticados. A conversa, portanto, entre técnicos e adolescentes, pode estar reduzida à comunicação das obrigações e deveres que o jovem deve cumprir durante a medida, ou ainda, a padrões de perguntas do tipo: se está se "comportando direito", se está tendo problemas na família, se está frequentando a escola e/ou se está trabalhando (em caso de medidas em meio aberto), com contribuições limitadas para o manejo do caso. Com a cultura do "não se pode falar no assunto", perdem-se informações indispensáveis para guiar estratégias de quando intervir (já que dados sobre o início da trajetória de delinquência é negligenciada nos dados oficiais) e de como intervir, intervenções mais generalistas ou mais específicas (já que dados quanto polimorfismo, uso de substâncias, frequentação de pares desviantes, motivação, dentre outras, também não são investigados). As respostas a essas perguntas trazem profundas implicações para o entendimento dos diferentes tipos de trajetória delinquente, se persistente e grave ou não (LeBlanc et al., 1991).

Se não se conhece de forma detalhada as características destes adolescentes, a intervenção é feita muitas vezes "às cegas", por ensaio e erro, com enormes custos para o serviço e sem o devido controle de sua eficácia. Além disso, se os problemas são subnotificados, não há como exigir ações públicas para o município. A delinquência auto-revelada dentro dos serviços pode, portanto, aperfeiçoar a coleta de informações, enriquecer os dados e conduzir ações mais realistas e assertivas junto aos adolescentes e suas famílias.

Dentro dessa perspectiva, a presente investigação tem como objetivo caracterizar a amostra de adolescentes que cumprem medida socioeducativa em meio aberto quanto a dois aspectos: a) características sócio-demográficas como idade, gênero, escolaridade, tipo de medida em meio aberto prestação de serviço à comunidade ou liberdade assistida; b) características quanto à gravidade de engajamento na delinquência: frequentação ou não da escola, idade do primeiro delito, tipos de delitos cometidos, presença de antecedentes criminais, frequentação de pares desviantes ou infratores, intoxicação por álcool ou drogas durante a passagem ao ato, uso de armas, planejamento, presença de cúmplices delinquentes, ausência de tensão durante a passagem ao ato, motivação utilitária e destruição de objetos durante a passagem ao ato. 


\section{MÉTODO}

Participantes

Trata-se de estudo descritivo, realizado mediante pesquisa documental, a partir de dados de arquivo do programa municipal de acompanhamento de adolescentes infratores submetidos a medidas socioeducativas, em regime de prestação de serviço à comunidade ou liberdade assistida. Foram para isso analisados os dados de prontuários de 211 adolescentes, de ambos os sexos, entre os meses de junho e dezembro de 2008, e identificadas as variáveis descritas nos itens $a$ e $b$ dos objetivos.

\section{Procedimento}

Em março de 2008, a equipe do serviço recebeu formação intensiva, ao longo de uma semana, oferecido por um grupo multidisciplinar do Canadá. Encerrada a formação intensiva, a equipe brasileira continuou sendo supervisionada, durante aquele ano, por um profissional brasileiro com doutorado em criminologia no Canadá, para a implementação da coleta de dados e das estratégias de intervenção a partir de dados da delinquência autorevelada.

A equipe passou a coletar junto aos adolescentes informações sobre sua prática infracional não oficial, ou seja, aquela não apreendida pela polícia e/ou sancionada pelo judiciário com vistas ao melhor conhecimento da trajetória de desenvolvimento do problema. A equipe fez uso de um roteiro de entrevista semi-estruturada baseado nos diferentes tipos de delito do Código Penal. Por exemplo: "Você alguma vez já comercializou drogas?", "Você alguma vez já comprou objetos roubados?", "Você alguma vez já dirigiu sem habilitação?".

Em caso de resposta afirmativa, investigava-se detalhadamente o delito quanto: presença de intoxicação durante a passagem ao ato, utilização de instrumentos (armas de fogo, facas ou outros), presença de planejamento, presença de cúmplices delinquentes, ausência de tensão durante a passagem ao ato, motivação e destruição de objetos durante a passagem ao ato. Ao fim, também foram investigadas a presença de antecedentes, precocidade (idade do primeiro delito) e frequentação de pares desviantes ou infratores. Essas variáveis têm sido apontadas pela literatura científica como parâmetros descritivos da delinquência juvenil (Le Blanc \& Fréchette, 1989). 
Cumpre informar que a pesquisa nos arquivos também coletou informações que permitissem descrever as características da amostra de adolescentes estudados: idade, sexo, escolaridade, frequentação da escola e medida socioeducativa seguida.

Os dados sócio-demográficos, assim como os relativos à delinquência autorevelada, foram organizados em planilhas no programa estatístico SPSS, procedendo-se as análises estatísticas de frequência e de tabulação cruzada.

Por questões éticas, é mantido o sigilo dos nomes obtidos no arquivo, seguindo as prerrogativas da Declaração de Helsinki.

\section{RESULTADOS}

A idade dos participantes variou entre 12 a 20 anos, com média de 16,6 anos e desvio-padrão de 1,5 anos. A média de escolaridade foi de 7,3 anos, com desvio padrão de 1,85 anos. No momento da coleta, 65\% da amostra não frequentavam a escola, sendo que $76 \%$ do total de adolescentes reconheceram ter faltado com frequência da escola sem justificativa (entre 3 a 4 vezes por semana). A idade do primeiro delito variou de 5 a 17 anos, com média de 12,2 anos e desvio padrão de 2,2 anos.

Tabela 1.

Distribuição do número de adolescentes da amostra segundo a idade no momento da coleta e a idade do primeiro delito auto-revelado $(\mathrm{N}=211)$.

\begin{tabular}{lcc}
\hline \multicolumn{1}{c}{ Anos } & Idade no momento da coleta (\%) & Idade do primeiro delito (\%) \\
\hline Até 11 & 0 & 40 \\
12 a 15 & 22 & 49 \\
16 a 17 & 48 & 11 \\
18 a 21 & 30 & 0 \\
\hline
\end{tabular}

A maior parte dos adolescentes possui entre 16 e 17 anos e cometeram seu primeiro delito entre 12 e 15 anos. É importante ressaltar que 40\% da amostra tiveram a idade do primeiro delito antes dos 12 anos (indicador importante para carreira criminal persistente).

Crimes contra a propriedade são os mais comuns entre os adolescentes, seguido dos crimes contra a pessoa. Os furtos aparecem como a categoria prevalente, correspondendo a 69\% dos adolescentes. Em segundo lugar aparece lesão corporal com $66 \%$ da amostra. 
Tabela 2.

Distribuição do número de adolescentes da amostra segundo o tipo de delito cometido de acordo com entrevista semi-estruturada $(\mathrm{N}=211)$.

\begin{tabular}{lcc}
\hline \multicolumn{1}{c}{ Ato infracional/ Contravenção } & Frequência & $\%$ \\
\hline Contra a propriedade & 146 & 69 \\
Furto & 138 & 65 \\
Receptação & 113 & 54 \\
Dano & 107 & 51 \\
Roubo & & \\
\hline Contra a pessoa ou costumes & 140 & 66 \\
Lesão Corporal & 128 & 61 \\
Rixa/desordem pública & 89 & 42 \\
Ameaça e Constrangimento Ilegal & 0 & 0 \\
Atentado ao pudor & & \\
\hline Crimes/delitos associados ao porte e tráfico de drogas & 108 & 51 \\
Tráfico de substância entorpecente & 102 & 48 \\
Porte de substância entorpecente & & \\
\hline Outras contravenções & 122 & 58 \\
Direção sem habilitação & 107 & 51 \\
Porte de arma & & \\
\hline
\end{tabular}

Os delitos associados ao porte e tráfico de drogas correspondem a aproximadamente metade da amostra. A taxa de prevalência de consumo de drogas, ainda que não mais considerado delito e, portanto, não indicado na tabela, se apresenta de forma robusta. Pelos menos 73\% da amostra relataram ter consumido alguma substância entorpecente, dentre elas, maconha $(70 \%)$ e/ou drogas duras (32\%).

Tabela 3.

Distribuição do número de adolescentes da amostra por número de tipos de delito cometido segundo a Escala da Delinquência Auto-Revelada $(N=211)$.

\begin{tabular}{lcc}
\hline Número de tipos de delito & Frequência & $\%$ \\
\hline 0 & 2 & 1 \\
1 a 5 & 40 & 19 \\
6 a 10 & 61 & 29 \\
11 a 15 & 55 & 26 \\
16 a 20 & 33 & 16 \\
Acima de 21 & 20 & 9 \\
\hline
\end{tabular}

Segundo os dados obtidos pelo Questionário de Delinquência AutoRevelada, os adolescentes cometeram de 0 a 30 tipos diferentes de delitos (desconsiderando a frequência de cada um dos delitos cometidos), com média de 
tipo de delito de 11,5 por adolescentes, com desvio padrão de 6,7. Os dois casos cujos resultados são zero correspondem às situações em que os adolescentes negam o cometimento do delito, mesmo cumprindo medida judicial pelo mesmo, e ambos correspondem a casos de atentado violento ao pudor.

Tabela 4.

Distribuição do número de adolescentes da amostra segundo variáveis indicadoras da gravidade do engajamento na delinquência ( $N=211)$.

\begin{tabular}{lcc}
\hline $\begin{array}{c}\text { Variáveis indicadoras de gravidade do engajamento } \\
\text { na delinquência }\end{array}$ & Frequência & $\%$ \\
\hline Frequentação de pares desviantes e/ou infratores & 158 & 75 \\
Motivação utilitária & 140 & 66 \\
Presença de cúmplices delinquentes & 132 & 63 \\
Presença de antecedentes & 105 & 50 \\
Ausência de tensão durante a passagem ao ato & 89 & 42 \\
Precocidade (antes dos 12 anos) & 85 & 40 \\
Planejamento & 77 & 36 \\
Presença de intoxicação durante a passagem ao ato & 74 & 35 \\
Utilização de instrumentos (ex: armas) & 72 & 34 \\
Destruição de objetos durante a passagem ao ato & 20 & 9 \\
\hline
\end{tabular}

Dentre as variáveis indicadoras de gravidade de engajamento na delinquência, a frequentação de pares desviantes ou infratores se apresenta como a mais comum delas (75\%), seguida de motivação para a obtenção de algum benefício material (66\%) e a atuação prioritariamente em grupos que sozinho (63\%). Também é relevante salientar que metade da amostra já havia cumprido alguma medida socioeducativa, já que 50\% apresentam antecedentes.

Prestação de serviço (PSC) versus Liberdade Assistida (LA)

Os adolescentes que cumprem medida sócio-educativa de LA representam $91 \%$ da amostra e os 9\% restantes cumprem PSC. Quando comparados os grupos que cumprem medida de PSC e de LA, não há diferenças significativas entre ambos no que diz respeito à escolaridade e idade do primeiro delito. Há, no entanto diferença significativa quanto à presença na escola, $x^{2}(1$, $\mathrm{N}=193)=11.819(p<0,001)$, enquanto na LA apenas $28 \%$ frequentavam a escola, na medida de PSC esse número sobe para $70 \%$. 
Tabela 5.

Média de idade, de escolaridade e de idade do primeiro delito segundo a medida sócio-educativa $(\mathrm{N}=211)$.

\begin{tabular}{lcc}
\hline \multicolumn{1}{c}{ Média } & PSC & LA \\
\hline Idade & 15,6 & 16,7 \\
Escolaridade & 7,3 & 7,3 \\
Idade do primeiro delito & 12,4 & 12,2 \\
\hline
\end{tabular}

Os dois grupos também diferem quanto aos tipos de delitos praticados. 0 grupo de LA apresentou frequência significativamente maior em tráfico de drogas, $X^{2}(1, N=211)=3.969(p<0,048)$; brigas e desordem pública, $X^{2}(1$, $\mathrm{N}=211)=3.953(p<0,047)$; roubo com arma de fogo, $X^{2}(1, N=211)=4.825$ $(p<0,02)$; presença de antecedentes criminais, $X^{2}(1, N=211)=5.739(p<0,017)$; frequência de pares desviantes, $X^{2}(1, N=210)=8.359(p<0,004)$; ausência de tensão durante a passagem ao ato, $X^{2}(1, N=210)=7.005(p<0,008)$ e motivação utilitária, $\mathrm{X}^{2}(1, \mathrm{~N}=210)=10.742(p<0,001)$.

Por exemplo, venda de drogas foi reportada por $30 \%$ dos adolescentes da PSC e por 53\% dos adolescentes da LA; envolvimento em brigas e desordem pública foi reportado por $40 \%$ dos adolescentes da PSC e por $63 \%$ da LA; roubo com arma de fogo, por $10 \%$ dos adolescentes da PSC e por $34 \%$ da LA; frequentação de pares desviantes por 50\% dos adolescentes da PSC e por 79\% da LA; ausência de tensão durante a passagem ao ato por 15\% dos adolescentes da PS e por $46 \%$ da LA e motivação utilitária por $35 \%$ dos adolescentes da PSC e por $71 \%$ da LA.

\section{Gênero}

O sexo masculino corresponde a $90 \%$ da amostra. Apesar do número de adolescentes do sexo feminino ser marcadamente inferior ao do sexo masculino, não há diferenças entre os grupos no que diz respeito à idade, escolaridade e idade do primeiro delito. Também a taxa de adolescentes do sexo masculino que frequentavam a escola foi similar à do sexo feminino, de $32 \%$.

O grupo de meninos apresentou frequência significativamente maior em roubo em um automóvel, $X^{2}(1, N=211)=4.290(p<0,038)$; furto de bicicleta ou moto, $X^{2}(1, \quad N=211)=8.913, \quad(p<0,003)$; receptação, $X^{2}(1, \quad N=211)=9.153$ $(p<0,002)$; roubo de uma pessoa, $X^{2}(1, N=211)=9.081 \quad(p<0,003)$ e porte de arma, $X^{2}(1, N=211)=6.686(p<0,01)$. Já o grupo de meninas apresentou 
frequência significativamente maior em furto na própria casa, $x^{2}(1$, $\mathrm{N}=211)=4.184(p<0,041)$ e fuga de casa, $x^{2}(1, N=211)=10.280(p<0,001)$.

Tabela 6.

Média de idade, de escolaridade e de idade do primeiro delito segundo o gênero $(\mathrm{N}=211)$.

\begin{tabular}{lcc}
\hline \multicolumn{1}{c}{ Média } & Masculino & Feminino \\
\hline Idade & 16,6 & 16,4 \\
Escolaridade & 7,3 & 6,9 \\
Idade do primeiro delito & 12,1 & 12,9 \\
\hline
\end{tabular}

Por exemplo, roubo em um automóvel foi reportado por 5\% das meninas e por $24 \%$ dos meninos; furto de bicicleta ou moto por $9 \%$ das meninas e por $42 \%$ dos meninos; roubo de uma pessoa por $5 \%$ das meninas e por $37 \%$ dos meninos; porte de arma por $5 \%$ das meninas e por $31 \%$ dos meninos; fuga de casa por $64 \%$ das meninas e por $30 \%$ dos meninos e furto dentro de casa por $27 \%$ das meninas e por $12 \%$ dos meninos.

\section{DISCUSSÃO}

A amostra do presente estudo é majoritariamente masculina, com $48 \%$ dos adolescentes possuindo entre 16 e 17 anos, taxas concordantes com as taxas fornecidas pelo relatório do ILANUD (2007). Os dados revelam uma taxa alta de abandono ou ausência na escola, com taxa de escolaridade muito aquém da média de idade da amostra, indicando que a escolarização, de uma forma geral, além de ser baixa, na maioria das vezes também foi interrompida. Desempenho pobre na escola, baixas aspirações acadêmicas e/ou evasão escolar aumentam significativamente o risco em que se encontram estes adolescentes de se engajarem em comportamento delinquente (Carroll, 2009).

A delinquência auto-revelada apontou que $40 \%$ da amostra cometeram o seu primeiro delito antes dos doze anos. Trajetória de comportamento desviante iniciada antes dos doze anos é indicador de precocidade da manifestação do problema. Precocidade, por sua vez, sugere maior risco e pior prognóstico ao adolescente, porque é um dos melhores preditores de carreira criminal persistente (Moffitt, 1993). A identificação da idade do primeiro delito tem implicações não somente para que se possa prever a gravidade da trajetória de comportamento anti-social, mas igualmente, para se definir estratégias de intervenção mais sofisticadas e específicas em casos de maior comprometimento. 
Os resultados mostraram ainda que a maior parte dos meninos (55\%) cometeram entre 6 e 15 tipos de delitos, com média de 11,5 por adolescente. Considerando que cada tipo de delito pode ter sido cometido múltiplas vezes (dado não disponível no presente estudo), o número total de delitos por adolescente é ainda maior. Adicionalmente, metade da amostra é primária. Isso significa dizer que metade dos meninos cumpre medida socioeducativa pela primeira vez, mas tem um histórico de tipos de delitos cometidos, em média, muito mais robusto que o único delito pelo qual cumpre medida. Provavelmente, a mesma lógica se aplica aos adolescentes com antecedentes. Isso ratifica a idéia de que se cometem muito mais delitos do que de fato o sistema de justiça é capaz de identificar e quantificar.

A taxa de 50\% de adolescentes reincidentes nos fornece também outra informação importante: metade dos adolescentes já passou por alguma medida socioeducativa, e, portanto, são adolescentes pós-intervenção. Dada a continuidade dos problemas, estes dados podem levar a algumas considerações: os serviços de medidas socioeducativas não estão cumprindo o papel a que se propõem e suas intervenções são pouco efetivas; o fenômeno da reincidência pode sinalizar medidas paliativas para a "contenção" do agir delituoso e um desajuste nas estratégias do serviço junto à rede social de apoio ao adolescente (família, bairro, escola, etc.).

Um dado importante que diz respeito indiretamente a questões na família e na frequentação da escola é a alta taxa de frequentação de pares desviantes (75\%) e da presença de cúmplices em pelo menos um dos delitos cometidos (63\%). O número de amigos delinquentes é um dos correlatos mais fortes de comportamento delinquente na adolescência. Adolescentes que reportam possuírem mais pares desviantes apresentam níveis mais altos de delinquência que adolescentes que têm pouco ou nenhum par desviante (Agnew, 1991; Warr \& Stafford, 1991). Pesquisas mostram uma forte correlação entre envolvimento com pares anti-sociais e supervisão parental (Dishion, Patterson, Stoolmiller, \& Skinner, 1991). Faltas repetidas na escola ou evasão escolar e menor tempo de supervisão dos pais podem levar a maior tempo despendido na rua, em atividades não estruturadas e fomentar o aprendizado social do crime. Os adolescentes têm, então, maior liberdade para se associarem a pares desviantes, porque também têm maior liberdade para selecioná-los e para se associarem a eles longe de seus pais e professores. Adolescentes que passavam mais tempo 
com seus pais tinham menor probabilidade de se associarem a pares delinquentes (Agnew, 2003). Estes são dados relevantes para um serviço de medidas socioeducativas por dois motivos. Primeiro, indica a necessidade de intervenção dos técnicos junto aos pais, no intuito de sensibilizá-los e instruí-los quanto à necessidade de maior supervisão das atividades diárias dos filhos e de despender mais tempo em atividades junto a eles. $E$ segundo, indica a necessidade de intervenção juntos aos adolescentes, com 0 intuito de desenvolverem atividades estruturadas de rotina (corroborando a importância da escola). Para ambos os casos, o intuito é minimizar o tempo nas ruas e, consequentemente, reduzir o tempo de contato com pares desviantes.

No que diz respeito aos delitos prevalentes, em primeiro lugar aparecem os crimes contra a propriedade, seguidos dos crimes contra a pessoa e/ou costumes, dados concordantes com aqueles apresentados pelo relatório do ILANUD (2007). No entanto, se considerados os delitos individualmente, o presente trabalho apresenta taxas prevalentes marcadamente superiores às taxas do referido relatório. Na presente pesquisa, furto, lesão corporal, receptação e rixa/desordem pública aparecem como as categorias prevalentes, representando delitos cometidos por pelo menos $60 \%$ da amostra. Os dados fornecidos pelo ILANUD (mencionados na introdução) consideram apenas o delito pelo qual o adolescente cumpre medida e apresentam categorias prevalentes distintas, a saber, roubo, furto, tráfico de drogas e porte de armas, e taxas muito inferiores, que variavam de 5 a $25 \%$.

Também no presente estudo, as taxas de delitos/contravenções, como ameaça, dano, dirigir sem habilitação e receptação variam de $42 \%$ a $65 \%$, enquanto que, no relatório divulgado pelo ILANUD, esses mesmos delitos/contravenções correspondem a delitos cometidos por menos de $3 \%$ dos adolescentes que cumprem medidas socioeducativas. Isso ilustra que os delitos mencionados, apesar de frequentes, só em raras ocasiões se transformam em processo judicial e entram nas estatísticas oficiais.

A comparação entre gêneros não revelou diferença entre meninos e meninas no que diz respeito à presença na escola, escolaridade e idade do primeiro delito. Apesar do grupo de meninos corresponder à imensa maioria da amostra, os $10 \%$ de meninas presentes no serviço parecem apresentar comprometimentos semelhantes ao grupo majoritário nestes aspectos. Um número significativamente maior de meninos, no entanto, relatou furto de moto 
ou bicicleta, roubo em um automóvel, receptação e porte de armas. Um número significativamente maior de meninas relatou fuga de casa e furto dentro da própria casa. Há necessidades de novas pesquisas no Brasil para se entender as diferentes etiologias da delinquência no que se refere a gênero.

Quando comparados os grupos de PSC e LA, os resultados revelam que o segundo grupo apresenta maior comprometimento psicossocial e maior frequência de índices de engajamento na delinquência: maior número de adolescentes com antecedentes criminais, com envolvimento de pares desviantes, com tráfico de drogas, com brigas, com roubos usando armas de fogo, ausência de tensão antes ou durante o delito e motivação utilitária. Esta discrepância revela a necessidade de formas distintas de intervenção para os dois grupos. O grupo da LA, o de maior risco, demandaria, deste modo, estratégias mais aprimoradas e específicas às suas peculiaridades.

\section{CONSIDERAÇÕES FINAIS}

Dados obtidos por meio de uma única fonte, o relato do adolescente, limita a validade e confiabilidade. Relatos de pares, dos pais e também de professores poderiam revelar, ou, não confirmar informações, implementando os resultados.

Outra limitação diz respeito ao fato de que o volume total de delitos cometidos por adolescente não foi considerado, apenas os tipos de delitos. Uma desvantagem da delinquência auto-revelada é que a taxa exata de quantas vezes um delito foi cometido, especialmente se muitas vezes, pode ter pouca confiabilidade (Pöge, 2007).

Trata-se de um estudo transversal, que por sua natureza é menos informativo. Há necessidade de novos estudos com acompanhamento longitudinal que façam inferências causais (Hinshaw, 1992), identifiquem fatores de risco e de proteção, assim como custos psicossociais e consequências adversas.

Uma das contribuições diz respeito à identificação de delitos cometidos através do auto-relato, trazendo índices mais robustos, e mais próximos do real, que os dados oficiais. O presente estudo também apresenta índices de engajamento na delinquência (idade de início, motivação utilitária, presença de cúmplices, de intoxicação ou uso de instrumentos durante a passagem ao ato, frequentação de pares desviantes, entre outros), dados que são, em geral, negligenciados em relatos oficiais, mas de importância central para o estudo do 
comportamento delinquente. Não são questões simplesmente acadêmicas, mas tem implicações na gestão de serviços e intervenção junto aos adolescentes e suas famílias (LeBlanc et al., 1991). Os profissionais que trabalham com intervenção estão diante de adolescentes cujo engajamento delinquente tem polimorfismo muito maior do que os dados oficiais são capazes de identificar.

Os dados obtidos no presente estudo corroboram a importância de se implementar a comunicação entre técnico e adolescente - eliminando a cultura do "não se pode falar sobre o delito"- e de se aprimorar e sistematizar a coleta de dados nos serviços. Isso pode trazer uma série de benefícios, descritos a seguir.

Primeiro, a delinquência auto-revelada possibilita reunir informação de todo o repertório comportamental delituoso do adolescente. Tal aspecto é essencial quando se quer analisar padrões de comportamento do adolescente (Pöge, 2007). Quando se conhece melhor sua dinâmica de funcionamento, seja ela de maior ou menor risco, maior a probabilidade da intervenção ser direcionada às demandas psicossociais do infrator.

Segundo, pode enriquecer os relatórios destinados ao juiz. Este, por sua vez, pode tomar decisões mais acertadas de manutenção ou não da pena, já que toma conhecimento de informações mais relevantes e pertinentes.

Terceiro, é possível que a implementação e uniformização da coleta de dados nos diferentes serviços de medidas socioeducativas facilitem o fluxo de informações na rede de atendimento do adolescente. Seriam diferentes serviços, mas uma única linguagem, mesmos princípios de atendimento e de intervenção. Quando a linguagem é comum, a comunicação é mais rápida e efetiva, e maior a probabilidade dos serviços trabalharem em conjunto e melhor.

Quarto, dados disponíveis sobre o fenômeno delinquência, obtidos a partir de metodologia rigorosa, podem desafiar falsas noções e concepções sobre crime. Problemas relacionados à delinquência juvenil estão entrelaçados numa complexa rede de inquietação, medo, indignidade pública e atenção da mídia (Hinshaw \& Lee, 2003). Mitos como "epidemia de delinquência", "não há o que se possa fazer", "a única saída é reduzir a maioridade penal" precisam ser empiricamente confrontados, porque geram situação de alarme na sociedade civil, levam a condutas de manutenção de segurança pública desacertadas e uso pouco hábil de recursos. 
Em suma, um bom sistema de informações sobre atendimentos pode enriquecer as análises, favorecer a decisão de gestores, planejadores, profissionais e organizações sociais. A melhoria do registro de serviços públicos, assim como o investimento na formação de pessoal subsidia o planejamento da expansão e da qualidade desta rede (Hoffmann, Santos \& Motta, 2008).

O Brasil, apesar de toda a problemática que apresenta em relação aos altos índices de criminalidade, que nos saltam aos olhos através da mídia, que dividem a opinião pública, tem ainda pouca pesquisa científica na área de desenvolvimento de trajetórias de comportamento delinquente. Apesar dos esforços brasileiros na melhoria na infra-estrutura de instituições destinadas a infratores menores de dezoito anos e na implementação das medidas socioeducativas, é necessário o urgente investimento em profissionais e pesquisadores que se ocupem do tema e que busquem soluções de prevenção e intervenção que condizem com a realidade do país.

\section{REFERÊNCIAS}

Agnew, R. (1991). The interactive effects of peer variables on delinquency. Criminology, 29, 47-72.

Agnew, R. (2003). An Integrated Theory Of The Adolescent Peak In Offending. Youth Society, 34, 263-299.

Carrol, A., Houghton, S., Durkin, K., \& Hattie, J. A. (2009). Adolescent reputation and risk: Developmental trajectories to delinquency. New York, USA: Springer.

Dishion, T.J., Patterson, G. R., Stoolmiller, M. \& Skinner, M. L. (1991). Family, school, and behavioral antecedents to early adolescent involvement with antisocial peers. Developmental Psychology, 27, 172-180.

Elliott, D. S., Huizinga, D., \& Morse, B. (1986). Self-report violent offending: A descriptive analysis of juvenile violent offenders and their offending careers. Journal of International Violence, 1, 472-514.

Fréchette, M. \& LeBlanc, M. (1987). Délinquances et Delinquants. Montréal: Gaëtan Morin Éditeur Itée.

Hinshaw, S. P. \& Lee, S.S. (2003). Conduct and oppositional defiant disorders. In E. J. Mash \& R. A. Barkley (Org.), Child Psychopathology (pp. 144-198). 2nd ed., New York: The Guildford Press. 
Hinshaw, S. P. (1992). Externalizing behavior problems and academic underachievement in childhood and adolescence: causal relationships and underlying mechanisms. Psychological Bulletin, 111, 127-155.

Hoffmann, M.C.C.L., Santos, D.N. \& Motta, E.L.A. (2008) Caracterização dos usuários e dos serviços prestados por Centros de Atenção Psicossocial Infanto- Juvenil. Cadernos de Saúde Pública, 24, 633-42.

LeBlanc, M., Côté, G. \& Loeber, R. (1991). Temporal paths in delinquency: Stability, regression, and progression analyzed with panel data from an adolescent and a delinquent male sample. Canadian Journal of Criminology, 33, 23-44.

LeBlanc, M. \& Fréchette, M. (1989). Male criminal activity from childhood through youth: Multilevel and developmental perspectives. New York: SpringerVerlag.

Liu, J. (2004). Childhood externalizing behavior: theory and implications. Journal of Child Adolescent Psychiatric Nursing, 17, 93-103.

Instituto Latino-Americano das Nações Unidas para Prevenção do Delito e Tratamento do Delinquente (2007). Mapeamento Nacional de Medidas Socioeducativas em Meio Aberto - Relatório Reduzido. Recuperado em 01 de janeiro de 2012, de http://www.ilanud.org.br/midia/doc/relatorio_resumido_mapeamento_mse_ abr2009.pdf

Moffitt, T. E. (1993). Adolescence-limited and life-course-persistent antisocial behavior: A developmental taxonomy. Psychological Rewiew, 100, 674-701.

Pöge, A. (2007). Klassifikationen und Verläufe Delinquenten Verhaltens: Eine Untersuchung Munsteraner Jugentlicher. Munster, Alemanha: Waxmann Verlag $\mathrm{GmbH}$.

Warr, M. \& Stafford, M. (1991). The influence of delinquent peers: what they think or what they do? Criminology, 29, 851-866.

Contato: Iyllacysne@yahoo.com.br

Recebido em: 13/12/2011

Revisado em: 18/12/2011

Aceito em: 30/12/2011 